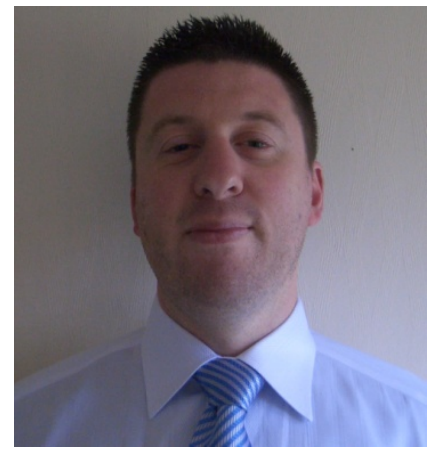

\title{
THE SHORT-RUN EFFECTS OF A \\ NATURAL DISASTER WITH \\ IMPERFECT INTERREGIONAL LABOUR MOBILITY
}

\author{
Nathaniel Robson \\ School of Economics and Finance \\ Victoria University of Wellington
}

\begin{abstract}
A multi-regional computable general equilibrium (CGE) model is used to simulate the short-run economic impact of a natural disaster that strikes the central business district of Wellington. A key feature of the analysis is the inclusion of an interregional migration response to the loss of regional amenity along with endogenous feedbacks from regional real wage relativities. The model economy describes the behaviour of twenty-five industries across five regions built upon bottom-up micro-foundations. The natural disaster scenario focuses on damage to capital of industries concentrated in the Wellington central business district and the flow-on effects via modelled relationships. The analysis of the simulation results considers the role that regional characteristics and interdependencies play in generating the computed short-run outcomes.
\end{abstract}

\section{Introduction}

In the wake of the Christchurch Earthquake of 2011, it is pertinent to consider the economic impact of a similar disaster occurring in Wellington in the present day, especially given its status as the country's capital and its seismic history. Along with the regional and national output and employment effects, aspects of interest include the resulting interregional migration flows and changes in key markets such as the housing market. A multiregional computable general equilibrium (CGE) model of the New Zealand economy is used to develop a scenario focusing on these issues. The CGE model - known as the JENNIFER model - was developed during the writing of a $\mathrm{PhD}$ thesis (Robson 2012) at Victoria University under supervision by Professor Viv Hall and Dr. Stephen Burnell.

The JENNIFER model is used to simulate the economic impact of a natural disaster within a scenario where a significant portion of the capital stock of Wellington's Central Business District (CBD) is destroyed or rendered temporarily inoperative. Interregional migration is modelled such that households respond to changes in relative regional amenity - defined as regional characteristics that enhance household utility (independent of consumption) - and relative real wage rates. For this scenario, these forces work in opposite directions: the loss of amenity in Wellington due to damage to infrastructure and the environment causes outmigration while the resulting bidding-up of real wage rates within the region induces in-migration. On net there is out-migration from the Wellington region and the average composition of the remaining households changes slightly. The main drivers of the simulation results are these scenario features and the behavioural assumptions and resource constraints contained within the CGE model core.

The results of the simulated scenario are presented in the next section. In the interests of brevity, a comprehensive description of the JENNIFER model is not given here; the interested reader is referred to the documentation in Robson (2012). Important modelling aspects will be highlighted as required in the discussion of the simulation results.

Due to the prototype nature of the JENNIFER model and uncertainties over parameter estimates, the results can only be taken as indicative of the effects of a natural disaster in Wellington. Potential model and scenario enhancements that would increase the reliability and usefulness of the simulation results are outlined in the penultimate section before concluding.

\section{The Scenario}

\section{Damage to Capital Stock}

The scenario concerns a disaster striking the Wellington CBD and therefore the capital damage is concentrated in the sectors that conduct their primary operations there: (percentage decrease in Wellington-located sectorspecific operational capital in brackets) government administration (15\%); communication, insurance, and finance services, real estate and equipment hire services, research and business services, education services, health services, transport services (all 10\%); accommodation, restaurants, and bars, cultural and personal services, retail trade, owner-occupied housing (all 5\%); electricity, water, and waste services, construction, wholesale trade 
(all 1\%). Overall Wellington loses about 8\% of its capital stock, equivalent to a $1 \%$ fall in the national total.

\section{Household Out-migration}

It is assumed that the disaster causes a fall in regional amenity such that, if there were no countervailing force, the Wellington region would lose 20,000 households to other regions and abroad. The basis for this assumption is the idea that households derive utility from regional amenity - the presence of infrastructure, convenience of urban or suburban dwelling, a pristine environment etc. and utility-maximising households will respond to changes in relative regional amenity by migrating.

Counterfactual simulations (not reported here) show that such an outward migration would result in a $25 \%$ increase in the average real wage rate in Wellington while that of other regions fall slightly. Even in the short-term, it is unlikely such a divergence in real wage rates would persist without any behavioural response by households. Instead, a rising real wage rate in Wellington would sufficiently compensate some households for the lower regional amenity, reducing the extent of out-migration and attracting households from other regions (and possibly from abroad). Once household sensitivity to relative real wage rates is taken into account, the outmigration of households is reduced to about 7,000, half of whom are assumed to move overseas.

\section{Short-run Setting and Macro Environment}

The setting of the scenario is necessarily short-run to allow the regional capital stock to be shocked. This has several implications for the environment under which the scenario is simulated. Most importantly, there is no linkage from investment to capital - aggregate investment is restricted to move in line with real GDP and while the allocation of the investment budget across industries and regions adjusts endogenously in response to changes in rates of return, the simulation horizon is too short for newly formed capital to come online.

Capital is therefore immobile between regions and industries. Labour on the other hand can move freely between industries, and partial mobility between regions is facilitated by the household migration response to regional real wage rate differences referred to above.

Two other assumptions are made due to the short-run setting of the scenario. First, real government expenditure is assumed constant: simulating a concurrent increase in public spending would complicate the interpretation of the results. Fairly soon after the disaster, additional spending will mainly consist of public investment towards rebuilding in which case a long-run simulation is more appropriate for investigating the effects of the fiscal response. The second assumption is that households save a constant share of their nominal income. Saving rates tend to only adjust slowly over time. In any case, the model lacks a micro-foundation for household behaviour with respect to saving due to its comparative-static nature.

An implication of the assumptions regarding investment, fiscal policy, and domestic private saving is that macroeconomic balance is restored by changes in the trade balance. Export volumes are determined according to downward-sloping export demand curves so import volumes adjust (at exogenously fixed world prices) to give the required change in the trade balance for equilibrium.

\section{Simulation Results}

Regional and national results are shown in Table 1 . The JENNIFER model calculates a post-shock general equilibrium and the associated percentage changes in model variables from benchmark values. The usual interpretation of these percentage changes is how the variables are predicted to differ from what they otherwise would have been had the shock (in this case the natural disaster scenario) not occurred.

The loss of factor inputs causes firms to cut back on production, driving up product prices. Since the shock originates in Wellington, the effect is much more pronounced there than at the national level. The sudden shortage of factors in Wellington pushes up their prices (wage and rental rates) to the extent that nominal income in the region rises. As consumption prices rise less than factor prices, real regional consumption increases (due to the assumption of a constant saving rate). With real regional income falling and consumption rising, the effect is a very large fall in real saving.

The effect for the other regions is the opposite. The net inflow of households from Wellington and subsequent expansion of labour supply puts downward pressure on wage rates. Despite the additional employment, nominal income falls leading to lower real consumption and higher saving. Nationally however the effects combine for lower real income, consumption, and saving.

The modelling of household behaviour includes a labourleisure choice such that labour markets can be in equilibrium without full participation. The results for Wellington indicate that while labour supply falls due to the net out-migration, there is also a shift from labour to non-labour market activities. At least some of the fall in participation is due to a composition effect: the participation rate in Wellington is initially higher than that of other regions, so to the extent that average Wellington households are replaced by average households from other regions by virtue of the net migration flows discussed above, the Wellington participation rate will fall. 
Table 1: Key regional and national results

Table 2: Gross industry output by region 
It is interesting to note that while the national result for real GDP per capita is as expected - a fall, suggesting a reduction in national welfare - this is actually due to lower real GDP per capita in the regions except Wellington, which itself sees an increase. This result is purely an outcome of the relative strengths of the assumed capital and migration shocks. Rather than surmising that the natural disaster is welfare enhancing for the residents of the affected region, what we can conclude is that at least in the short-term, net migration from the region where the disaster occurs can go some way to mitigating the associated welfare costs.

Percentage changes in gross output across industries and regions are shown in Table 2 . These results are able to be obtained due to the bottom-up regional structure of the model. That is, since each region is modelled as an interdependent economy within the national aggregate, regionally located firms and households face regionspecific prices and supply constraints. The implications of this modelling approach can be seen by looking at the results of a few industries in Table 2 . Although government administration saw a larger decrease in its capital stock (-15\%) than research and business services $(-10 \%)$ and accommodation, restaurants, and bars $(-5 \%)$, the output of the former falls less in Wellington than in the latter two industries. This is for two reasons: first, most government administration activity takes place in Wellington. The shortage of operational capital outside Wellington after the shock makes shifting operations difficult. The second reason is that there is no importable alternative to domestically produced government administration so import substitution does not occur. This is not the case with the other two industries households and firms can easily substitute Wellington accommodation for the same elsewhere in New Zealand or abroad, for example. Faced with higher accommodation prices in Wellington (due to the sudden factor shortage), agents (both domestic and foreign) shift their demand towards the varieties available in other locations.

The industry/sector 'ownership of owner-occupied dwellings' is a proxy for imputed rents from home ownership. This sector, along with education and health, is assumed to be a local industry - that is, each sector's product is only sold to agents (mainly households) within its region of production. This means there is no opportunity to substitute towards other regional varieties when there is a change in relative prices and in the case of ownership of owner-occupied dwellings, there is no imported variety either. Thus the decrease in output for these industries is less than for those mentioned above where more substitution opportunities exist. The changes in output of the local industries in regions outside Wellington are indirect effects of the shock - the net migration flows to other regions results in higher demand for health services in those regions, for example, pushing up the regional equilibrium prices and levels of output.

\section{Potential Enhancements}

The analysis of this paper could be enhanced by either developing a more detailed scenario that can be simulated within the current modelling framework, or by augmenting the model to add new behavioural relationships and provide more detail. One aspect of the scenario that could be developed is the fiscal response. While new government expenditure on products will mainly be new investment spending and therefore a longrun (and ideally dynamic) simulation environment is more appropriate, transfers to households would increase significantly in the short-run and the effect of these transfers could be investigated. Another area worthy of consideration is the potential impact of the disaster on export markets, particularly tourism and related services, and how this would affect relative regional performance.

Of the many possible model enhancements, two stand out as particularly relevant for natural disaster scenarios similar to that developed here. The first is the specification of different household types and/or classes of labour. This would enable richer detail regarding the response of households to the disaster (in terms of their responsiveness to both amenity and real wage rate changes). For example, one may wish to investigate the impact of different levels of mobility amongst skilled vs. unskilled or small vs. large households. The other important potential model improvement would be the addition of dynamic elements. This would allow a longrun scenario to be developed where, after the initial disaster, rebuilding takes place and the model keeps track of the time path of investment and capital. Moving to such a comparative-dynamic modelling framework would also allow for the inclusion of household and investment behaviour that incorporates expectations.

\section{Conclusions}

Results of a natural disaster scenario simulation produced by the JENNIFER multi-regional CGE model have been presented in this paper to illustrate how the model can be applied to policy issues and the kind of analysis that can result from such applications. Some key aspects of the modelling framework have been highlighted along the way. Broadly speaking, the model is comparative-static in nature and built upon bottom-up micro-foundations. There are many aspects of the model and scenario which may be developed to provide further interesting and useful results. The current state-of-the-art dictates that one of the first enhancements should be to expand it to become a comparative-dynamic model.

\section{References}

Robson, N. (2012). A Multi-Regional Computable General Equilibrium Model for New Zealand. $\mathrm{PhD}$ thesis, Victoria University of Wellington. URL:

researcharchive.vuw.ac.nz/handle/10063/2319 